UDC: 811.111:33(510) https://doi.org/10.22190/JTESAP1801115S

\title{
EXPLORING COURSE DESIGN FOR A UNIVERSITY-LEVEL ESP- BASED COLLEGE ENGLISH PROGRAM AT UNIVERSITY OF FINANCE AND ECONOMICS IN CHINA
}

\author{
Wenjie Shi \\ School of Foreign Studies \\ The Central University of Finance and Economics, China \\ Telephone: +86-10-62288646; E-Mail: wenjieshi@cufe.edu.cn
}

\begin{abstract}
By undertaking needs analysis of the learners, teachers and prospective job positions regarding the language skills and language contents, this study identified the students' needs in terms of language skills and preferred contents, and then combined EFL teachers' academic expertise with the needs of other immediate stakeholders before devising an updated College English Program featured by ESP-based courses for finance and economic purposes available to students. Empirical studies on the effectiveness of the newly designed College English Program showed that the satisfaction is higher than that for EGP-based courses, and students' learning motivation and classroom engagement were boosted in ESP-based courses for finance and economic purposes.
\end{abstract}

Key words: needs analysis, English for Specific Purposes, course design

\section{INTRODUCTION}

This study took place in the context of a nationwide reform of College English Program undertaken by universities in China, in order to accommodate the students' extended and diversified needs towards English language courses. Whilst much theoretical research has been conducted regarding reform of the college English curriculum (Wen, 2012; Zhan, 2014; Zhang \& Ma, 2015) in an attempt to suit learners' needs for English in specified academic register, empirical research has as not yet been undertaken regarding the learners' needs of universities of finance and economics, which is a growing students body in China as disciplines of economics and finance are widely prevailing among university entrants. This study aimed to answer the following research questions:

(1) What are perceptions of English language courses for the students in university of finance and economics?

(2) What are the learners' needs to English language courses in terms of language skills and preferred contents, and the expectations of faculty in disciplines of finance and economics and professionals in the financial service sector?

(3) How will the students respond to the ESP-based College English Program in terms of satisfaction with the delivery of the courses? 


\subsection{College English Program in China}

College English Program as a mandatory courses cluster for most of the university students that used to include College English Courses from Level 1 to level 4, which focused on developing language skills of listening, reading, speaking, writing and translating designated for students at varied proficiency. Over the past three decades, College English Program gave much priority to English for general purpose that attached importance to general reading and communicative functions, neglecting speaking and writing skills. Therefore, Teaching English as a Foreign Language (TEFL) in China has received a wide range of complains and blames from main stakeholders like the government, educational authorities and institutions, employers in various industries and business, students and parents of students in different levels, and transformation of College English Program has been studied by EFL practitioners (Cai, 2011, 2012; Li, 2016; Wen, 2012).

The scenario that College English Program failed to live up to the needs and expectations held by related stakeholders can be attributed to multiple reasons, like outdated syllabus, obsolete pedagogical beliefs and teaching practice implemented by schools and institutions, input-focused teaching material and technology employed widely by teachers and instructors at various levels, test result-oriented learning motivations massively accepted by Chinese EFL learners and stakeholders, and English for General Purpose (EGP) dominated language instruction widely adopted from beginner learners in primary schools to intermediate learners in universities (Wang, 2011).

\subsection{ESP-based College English Program reform in CUFE}

Over the past decade, a new wave of College English Program reform has generated widespread concern, which featured Content-Based Instruction (CBI) and English for Specific Purpose (ESP) to meet higher learning needs and expectations from university students who are enrolled in top or key universities in China (Wang, 2011; Zhang, 2011).

ESP-based language learning and instruction differentiate from EGP-based modes in that the ESP-based program and courses are designed on the basis of learners' specialized needs and expectations (Hutchinson \& Waters, 1987; Steven, 1988), which are derived from the disciplines and future professional domains. In addition, ESP-based program and courses attach more significance to contents of disciplines than to language skills themselves, thereby language acquisition is taking place along with the study of subject knowledge in different disciplines (Dudley \& John, 1998).

Following the reform trend in China TEFL domain, Central University of Finance and Economics (hereafter abbreviated as CUFE), one of the top universities of finance and economics in China regarding the teaching and research excellence of faculty and enrolled students' aggregated individual scores achieved in the National College Entrance Exams, launched a College English Program reform in hope of designing high-quality College English Program to meet the students' needs in foreign language learning.

A research team from School of Foreign Studies was commissioned following competitive application to upgrade College English Program. The project aims to create a new College English Program based the existing one to meet the students' diversified learning needs, and to build up students' communicative skills in foreign languages, to make the students use the language proficiently in workplace and academic exchange settings upon completing the program. 


\subsection{Needs analysis among main stakeholders}

Needs surveys for devising the ESP-based courses were conducted by the research group on three stakeholders of the courses, namely the undergraduate students, graduates from CUFE who work in financial services sector, and faculty of finance and economics in the university. We adopted online questionnaires and structured interviews to identify the needs and motivations held by students on English language learning, expectations held by financial professionals with respect to foreign language skills and abilities to would-be graduates from universities of finance and economics, expectations on English language courses from faculty of business and finance disciplines.

\section{METHODS}

An online questionnaire survey was conducted among the students enrolled in the autumn of 2013 at the academic year of 2014/15, when the students have completed the 2-academic years English courses, a total valid number of 515 student participated and completed the online questionnaire regarding their motivations of learning the English language, needs and wants for the college English courses.

The findings of the school-level investigation were analyzed against the backdrop of College English Program reform in hope that we would devise a new learners' needs-based College English Program featured by courses of English for Specific Purposes.

To find the effectiveness of the new ESP-based College English Program, a similar investigation of students' learning needs and motivations was administrated among the students enrolled in the autumn of 2014 at the academic year of 2015/2016, and a comparative study of feedbacks to the satisfaction of the courses featured by EGP and ESP was conducted with a random sample of 124 participants who were enrolled in the autumn of 2014.

\subsection{Data collection and analysis}

\subsubsection{Perception and motivation of learning college English language courses}

With regard to the perception of English language courses for those students investigated, Table 1 shows that the vast majority of the respondents $(90.09 \%)$ believe that English language skills are of importance to future academic performance and employability after having completed study periods of bachelor degrees, with 56.50 of the respondents deeming English language skills as 'very important', and 33.59 of them believing 'important'.

Table 1 Perception of English language courses

\begin{tabular}{lcc}
\hline \multicolumn{3}{c}{\begin{tabular}{c} 
Perception of the importance of English language courses \\
\multicolumn{2}{c}{ for academic and career development $(\mathrm{N}=515)$}
\end{tabular}} \\
\hline Options & Number of respondents & $\%$ \\
Very important & 291 & 56.50 \\
Important & 173 & 33.59 \\
Neutral & 46 & 8.93 \\
Less important & 3 & 0.58 \\
Not important & 2 & 0.39 \\
\hline
\end{tabular}


Furthermore, they were surveyed on the motivations of learning English language courses, which were ranked and weighted based on the students' options adding up to averaged rankings, which are shown in Table 2 . The averaged rankings were interpreted that smaller numbers mean higher priority attached to the motivations. Consequently, it is interesting to notice that the top two motivations are:

- to pass the College English Test Band 4 and 6;

- to secure a decent job in the job market.

There was a marginal gap between the top two motivations with averaged ranking of 2.79 and 3.17 respectively, and the least important motivations, which are:

- to meet individual needs for interests in English language with averaged ranking of 3.62 ;

- to improve their foreign language literacy with averaged ranking of 3.71,

- to prepare for going abroad with averaged ranking of 3.85,

- to get the required credits of English courses embedded in the degree program with averaged ranking of 3.86 .

Table 2 Motivation of learning English language courses

\begin{tabular}{lrllllll}
\hline \multicolumn{3}{c}{ Ranking of motivations of learning English language by priority $(\mathrm{N}=515)$} \\
\cline { 2 - 7 } The motivations of learning English & \multicolumn{5}{c}{ Priority rating } & Averaged \\
language are for: & $9 \%$ & $15 \%$ & $19 \%$ & $18 \%$ & $18 \%$ & $21 \%$ & 3.86 \\
\hline credits required & $16 \%$ & $13 \%$ & $16 \%$ & $20 \%$ & $20 \%$ & $15 \%$ & 3.62 \\
individual interests & $18 \%$ & $13 \%$ & $11 \%$ & $12 \%$ & $17 \%$ & $29 \%$ & 3.85 \\
going abroad & $27 \%$ & $23 \%$ & $18 \%$ & $15 \%$ & $11 \%$ & $7 \%$ & 2.79 \\
passing CET-4/6 & $15 \%$ & $23 \%$ & $23 \%$ & $17 \%$ & $13 \%$ & $9 \%$ & 3.17 \\
securing better jobs & $15 \%$ & $14 \%$ & $14 \%$ & $18 \%$ & $20 \%$ & $19 \%$ & 3.71 \\
linguistic and cultural literacy & & & & & & &
\end{tabular}

We can assume that to pass CET-4/6 and secure a good job can be considered as highly instrumental motivations for the students, as they learn the language courses with a primary purpose to gain the skills and knowledge of English language that will be tested in the CET-4/6, whereby with an accreditation of language proficiency by the tests they are more likely to find a better job by the time of graduation.

College English Tests Band 4 and 6 (CET-4/6) were proficiency tests developed by the State Education Commission in 1988 to assess the undergraduates' proficiency \& achievement attained from the college English courses, and to ensure that students will have reached the levels prescribed by the College English Teaching Syllabus on completion of the degree program. College English Tests are nationwide high-stake test with formidable impacts for undergraduates: Failure in the CET-4 by the time of graduation might disqualify the applicants' university degrees.

Meanwhile, the respondents ranked the motivation of interest and foreign language literacy following CET-4/6 and securing a good job, which might indicate that they have some integrative motivations in learning the English language courses, but the integrative motivation is less significant than the instrumental ones.

Learning the language for preparedness of studying abroad or readiness to get the credits involved in the language courses can similarly be categorized as instrumental motivations. 
The responses to these two items in the questionnaire indicate that the respondents attached critical importance to English language skills to be acquired in the College English Courses, and that their motivations for learning the language courses can be both instrumental and integrative, where instrumental motivations were more noticeably demonstrated than integrative ones for these students.

Previous literature on motivations of language learners suggests that both motivations will contribute to learners' success with varying impact to learners' learning behaviors, and that learners with integrative motivations are more likely to long-term success than learners with instrumental motivations (Zoltán, 1990).

Therefore, we arrived at the conclusion that these students are with strong motivation to learning English language, and are likely to succeed in their learning outcomes as long as the appropriate language courses and teaching approaches are provided for them.

\subsubsection{Needs analysis of language skills}

With regard to the ranking of English language skills in which they are weak, speaking and listening were considered as the top two weakest skills, followed by writing, translating and reading respectively, as illustrated in Table 3.

Table 3 Ranking of weak language skills

\begin{tabular}{lcc}
\hline \multicolumn{3}{c}{ Self-identified weak language skills (N=515) } \\
\hline Options & $\%$ & No of Options \\
\hline Listening Comprehension & 55.92 & 288 \\
Speaking Abilities & 67.57 & 348 \\
Reading Comprehension & 22.91 & 118 \\
Writing Skills & 48.35 & 249 \\
Translating Skills & 29.90 & 154 \\
\hline
\end{tabular}

These findings of self-identification of language skills by Chinese EFL learners at tertiary level, to a great extent, echoes with the statistics of research findings by IELTS test performance newsletter as illustrated in Table 4 (IELTS Test taker performance 2015), where assessment data showed that IELTS test takers of China origin were particularly weak in writing, speaking and listening in terms of the individual band scores achieved in IELTS (Academic) in the year of 2015.

Table 4 Mean band score for the test takers of China origin (Academic) 2015

\begin{tabular}{lccccc}
\hline \multicolumn{6}{c}{ Mean band score for the test takers of Chinese origin (Academic) } \\
\hline Place of origin & Listening & Reading & Writing & Speaking & Oevrall \\
\hline China (People's Republic of) & 5.9 & 6.1 & 5.3 & 5.4 & 5.7 \\
\hline Source: data from Mean band score for the most frequent countries or regions of origin (Academic)
\end{tabular}

With regard to ratings of the language skills that the respondents want for study and communication, unsurprisingly, speaking and listening skills are regarded as the two skills that they are most eager to improve, followed by writing, reading and translation. 


\subsubsection{Needs analysis of preferred contents in language courses}

An entry was included in the questionnaire with regard to the students' preferred contents covered in the English language courses, which are illustrated in Table 5. The contents featured by tasks to improve practical communicative abilities was the top option $(85.44 \%)$, which was followed by contents related to their own subject disciplines with a huge margin (46.99), contents related to improve their test-taking skills (37.09), and contents related to general linguistic and cultural domains (22.14).

Table 5 Preferred contents of instruction for College English courses

\begin{tabular}{lrr}
\hline \multicolumn{3}{c}{ Preferred specific contents of instruction for College English Courses (N=515) } \\
\hline Options & $\%$ & No of Options \\
Courses based on subject knowledge in disciplines of finance and economics & 46.99 & 242 \\
Courses to improve communicative abilities in practice & 85.44 & 440 \\
Courses to prepare them for English languages tests & 37.09 & 191 \\
Courses to boost linguistic and cultural literacy & 22.14 & 114 \\
Others & 0.58 & 3 \\
\hline
\end{tabular}

The follow-up interview with the respondents with a purpose to figure out the students learning needs in terms of preferred contents suggested that the students were highly motivated to engage themselves to the contents of tasks that are designed to improve their practical communicative competences in their specified academic disciplines, which is based on the underpinning assumption that there was a shortage of focused contents on English for finance and economic purposes, and instead was a redundant supply of contents on English for general language or cultural purposes.

Similarly, structured interview with representative teachers in the disciplines of finance and economics indicated that the teachers believed that what the students need most in terms of language knowledge is not grammar or general vocabulary, but specified technical terms in business and finance discipline for academic reading, presentation and writing.

With regard to the English language skills demand of financial companies and preferred teaching contents in English courses, we conducted a survey and interview among professionals in banking and financial service companies who were alumni of CUFE.

It is surprising that there is not a high demand for English language skills if the department is not immediately international business related, and for employees working in international business-related department of financial companies and those who plan to be transferred to international business-related department, higher speaking and writing abilities in specified finance and economics domain will be required.

The surveys and interviews allowed researchers to obtain an overall analysis of the target situation needs of language skills and contents, the learners' wants of language skills and contents in language courses and the gap between the demands from target language use situations and current supply of language skills and contents included in the courses. Combining the learning needs of the students surveyed, expectations from teachers in financial and economic disciplines and from professionals in financial services business, we concluded that for university students who have obtained adequate knowledge of English grammar in high school intensive study and were enrolled in top universities in China, their language learning demands were more focused on improving communicative abilities in practice in the context of more specified academic or professional settings. 


\section{DeSIGNING A NEEDS-BASED ESP COLLEGE ENGLISH PROGRAM}

In order to suit the extended and specified needs of the students, we launched an initiative for EFL teachers to offer English courses of specific purposes instead of English for General Purposes by integrating their academic expertise in the specifically focused English courses for academic and professional preparedness demanded by the students.

In the wake of data collection and analysis, we designed an updated College English Program as in Table 6, in which the courses are based on students learning needs and wants, EFL teachers teaching expertise, and prospective employers' expectations to the graduates' language proficiency.

Table 6 Multi-module College English Courses based learning needs and teachers' expertise

\begin{tabular}{llc}
\hline Modules & Courses Proposed by faculty & $\begin{array}{c}\text { No of } \\
\text { Teachers }\end{array}$ \\
\hline EAP \& ESP & $\begin{array}{l}\text { English for Academic Purpose } \\
\text { Business English for Finance and Economics Purpose } \\
\end{array}$ & 2 \\
& Selected Readings from English Media for Business and & 6 \\
& Finance Purpose & 2 \\
& English in the News & 1 \\
\hline Advanced skills in & English Debating and Current Issues & 1 \\
English language & Chinese-English Translation & 2 \\
& Public Speaking in English & 1 \\
\hline Culture and & Selected Readings of American Fiction & 2 \\
literature & The History and Culture of the USA & 2 \\
& History and Culture of the UK & 1 \\
\hline
\end{tabular}

The courses include EAP and ESP module like English for Academic Purpose, Business English for Finance and Economics Purpose, Selected Readings from English Media for Business and Finance Purpose and English in the News; advanced language skills development module such as English Debating and Current Issues, Chinese-English Translation, Public Speaking in English; cultural and literature module including Selected Readings of American Fiction, The History and Culture of the USA, History and Culture of the UK.

The new College English Program allows the students to choose the courses available based on their interest and learning needs instead of previously mandatory courses that were almost the same EGP courses for all the students. The students, however, are allowed to choose the same one course only once if they don't get a fail in the final assessment of the chosen course, which is regulated for maximum availability of the courses to widened student body.

\section{LEARNING OUTCOMES OF THE STUDENTS}

A total number of 1963 students registered the multi-module ESP based College English Courses on the basis of a first-come-first-serve online registration system, because of the limited availability of course types and limited seats capacity of the classroom. The distribution of the students who registered for different ESP-based courses can be illustrated by Table 7: 
Table 7 Percentage of the courses registered by the students

\begin{tabular}{lcc}
\hline Courses Available & $\begin{array}{c}\text { No of registered } \\
\text { students }\end{array}$ & $\begin{array}{c}\text { \% of the students } \\
\text { against the total }\end{array}$ \\
\hline Business English & 726 & 36.98 \\
Selected Readings of American Fiction & 264 & 13.45 \\
English for Academic Purpose & 262 & 13.35 \\
The History and Culture of the USA & 225 & 11.46 \\
Selected Readings from English Media & & \\
for Business and Finance Purpose & 138 & 7.03 \\
English Debating and Current Issues & 138 & 7.03 \\
Chinese-English Translation & 128 & $6.52 \%$ \\
English in the News & 82 & $4.18 \%$ \\
\hline Total & 1963 & $100.00 \%$ \\
\hline
\end{tabular}

We undertook an investigation over the effect of the new program and the result showed that the students are more motivated to choose their favorite courses, are more actively involved in classroom activities, and more supportive of the new College English Program. Feedbacks from prospective employers are to be collected and further analyzed by the time when these students will have completed their studies and placed themselves on the job positions.

\subsection{Feedback from faculty in finance and economics disciplines and EFL faculty}

Faculty and teachers from finance-related departments gave positive comments on the new program, through which the student are able to connect what they have learned in English classroom with the courses of their specialties, which will facilitate the delivery of courses for subjects of specialties in English and reading academic literature in English. Feedbacks from the EFL teachers involved in the project with their ESP courses are mixed; among them most of the participating teachers support the new College English Framework even it has put a lot of extra workload on them. There are issues to be settled on ESP course design and delivery, like course syllabus writing and standards for teaching of each individual course, quality assurance procedure, teacher development and faculty support from the department and university, assessment and outcome of the ESP-based courses, to mention a few.

Additionally, the course modules offered in the new College English Program have not sufficiently met the students' diversified needs and expectations, the students are in eager need of writing courses in English, and they need translation and interpretation courses too, they expect that the teachers can be more competent in the fields of specialties knowledge.

\subsection{Learning outcomes of the students to the new ESP-based College English Program}

By the completion of the two consecutive terms of ESP-based College English Courses, we investigate the students' feedback to the ESP-based courses, which was compared with the previous EGP-based college English courses the respondents had taken prior to the ESP-based courses.

It is evident from the statistics illustrated in Table 8 that the respondents are noticeably more satisfied with the ESP-based courses than with the EGP-based courses. 
Table 8 Comparison of satisfaction for EGP and ESP-based courses

\begin{tabular}{lcccr}
\hline \multicolumn{4}{c}{ Comparison of satisfaction for EGP and ESP-based courses (N=124) } \\
\hline EGP Satisfaction & \multicolumn{3}{c}{ ESP Satisfaction } \\
\hline Options & No of Options & $\%$ & No of Options & $\%$ \\
\hline Very Satisfied & 9 & 7.26 & 5 & 4.03 \\
Satisfied & 37 & 29.84 & 57 & 45.97 \\
Neutral & 62 & 50.00 & 54 & 43.55 \\
Less Satisfied & 14 & 11.29 & 8 & 6.45 \\
Not Satisfied & 2 & 1.61 & 0 & 0.00 \\
\hline
\end{tabular}

Statistically, the satisfaction rate (including very satisfied with a ratio of 45.97 and satisfied 4.03) for ESP-based courses was 50\%, which is higher than that (37.10) for EGP-based courses ((including very satisfied with a ration of 29.84 and satisfied 7.26).

We explored the reasons for the changes of satisfaction by interviewing students, which can be attributed as the following:

(1) The availability of multi-module of ESP-based College English Courses enable most of them to register the courses of their primary interests, which was likely to motivate them to be more engaged in the courses they registered;

(2) The teaching contents of the ESP-based College English Courses are more specified to the disciplines of their fields, which would give them more motivation to actively learn the courses;

(3) The updated College English Program give more priority to developing the students' communicative abilities in practice for academic or professional purposes.

\section{CONCLUSION AND DISCUSSION}

The study devised a needs-based ESP College English Program for finance and economics purposes, which was evaluated to be more satisfying in terms of the overall course delivery than previous EGP College English Program.

EFL practitioners who joined this program ESP-based instruction are facing a fresh and focused academic horizon for career development, which are likely to create more opportunities for theoretical and empirical studies in future.

It is obvious, however, that there are a couple of upcoming issues of controversy and even doubts among the EFL teachers and students, among which are:

(1) The teachers are inadequate in confidence when they are delivering courses of ESP-based, with courses in the track of economics and finance in particular.

(2) The teachers are puzzled about their self-identity when delivering ESP-based English courses, that is, they are confused about whether they are language teachers or subject course teachers.

(3) The conclusion that students' satisfaction was higher for ESP-based courses is unlikely to guarantee that the students are satisfied with the courses as the needs from students are growingly diversified and demanding.

Therefore, the sustainability and diversity of the ESP-based courses were challenged by limited faculty resources of qualified EFL teachers. Future longitudinal studies are expected to be undertaken regarding teacher identify, teaching strategies, learning strategies and assessment issues to justify the effectiveness of the new ESP-based College English Program. 
Acknowledgement: This study is part of the research findings from the project titled The Study of ESP Instruction and Assessment for Universities of Finance and Economics in the Context of a New College English Program sponsored by Central University of Finance and Economics to whom I extend my thanks.

\section{REFERENCES}

Cai, J. A way out for EFL at Tertiary Level Education in Mainland China, Shanghai: Shanghai Jiaotong University Press, 2011.

Cai, J. "A study of ESP College English mode based on needs analysis." Foreign Languages Teaching no. 3 (2012): 47-50.

Dudley-Evans, T. and M. J. St John. Developments in English for specific purposes: A multi-disciplinary approach. Cambridge: Cambridge University Press, 1998.

Hutchinson T. and Waters A. English for Specific Purposes-A Learning-Centered Approach. Cambridge: Cambridge University Press, 1987.

Jacoby, S. and McNamara, T. "Locating competence." English for Specific Purposes, 18, no. 3 (1999): $213-241$.

Li, H. "On guideline for college English teaching and challenges for college English teachers." English Language Teaching no. 9 (2016): 77-87.

Ministry of Education. College English Curriculum Requirements, Shanghai: Shanghai Foreign Language Education Press, 2007.

National College English Teaching Advisory Board. College English Teaching Guidelines (Version inviting suggestions), 2015.

Stevens, P. "ESP after Twenty Years: A Re-appraisal." In ESP: State of the Art, edited by Tichoo, 1-13. Singapore: SEAMEO Regional Language Centre, 1988.

Wang, S. and Wang, H. "An investigation into the current situation of College English teaching among colleges and Universities in China and its reform and developing directions." Chinese Foreign Languages 8, no. 5 (2011): 4-10.

Wen, Q. "The challenges and solutions for College English from the perspectives of curriculum theories." Foreign Languages Teaching and Research 44, no. 2 (2012): 283-92.

$\mathrm{Wu}, \mathrm{H}$., and R. G. Badger. "In a strange and uncharted land: ESP teachers' strategies for dealing with unpredicted problems in subject knowledge during class." English for Specific Purposes 28, no. 1 (2009): 19-32.

Zoltán Dörnyei. "Conceptualizing Motivation in Foreign-Language Learning." Language Learning 40, no 1 (1990): 45-78.

Zhan J. "Reforming English education in the mainland universities of economics and finance to meet the demands of the 21st century: research on the teaching methods of content-based English instruction for specific business purposes." in Research of Contemporary Foreign Languages no. 3 (2014): 22-32.

Zhang, W. "Comparative Analysis of College English Syllabi -From the Ecological Perspective.” Modern Education Science 8, no 3 (2011): 149-150.

Zhang, X., and Ma R. "A Study of ESP teaching and research in Asia." Research of Contemporary Foreign Languages no. 8 (2015): 43-47.

Central University of Finance and Economics, accessed Dec 1,2017, https://en.wikipedia.org/wiki/Central_University_of_Finance_and_Economics

IELTS Test taker performance 2015, accessed Dec 1, 2017, https://www.ielts.org/ teaching-and-research/test-taker-performance 